\title{
Biological network inferences for a protection mechanism against familial Creutzfeldt-Jakob disease with E200K pathogenic mutation
}

Sol Moe Lee ${ }^{1,3+}$, Myungguen Chung ${ }^{2,4 \dagger}$, Kyu Jam Hwang ${ }^{1}$, Young Ran Ju', Jae Wook Hyeon', Jun-Sun Park', Chi-Kyeong Kim', Sangho Choi', Jeongmin Lee ${ }^{1}$ and Su Yeon Kim ${ }^{1 *}$

\begin{abstract}
Background: Human prion diseases are caused by abnormal accumulation of misfolded prion protein in the brain tissue. Inherited prion diseases, including familial Creutzfeldt-Jakob disease (fCJD), are associated with mutations of the prion protein gene (PRNP). The glutamate (E)-to-lysine (K) substitution at codon 200 (E200K) in PRNP is the most common pathogenic mutation causing fCJD, but the E200K pathogenic mutation alone is regarded insufficient to cause prion diseases; thus, additional unidentified factors are proposed to explain the penetrance of E200K-dependent fCJD. Here, exome differences and biological network analysis between fCJD patients with E200K and healthy individuals, including a non-CJD individual with E200K, were analysed to gain new insights into possible mechanisms for CJD in individuals carrying E200K.
\end{abstract}

Methods: Exome sequencing of the three CJD patients with E200K and 11 of the family of one patient (case1) were performed using the Illumina HiSeq 2000. The exome sequences of 24 Healthy Koreans were used as control. The bioinformatic analysis of the exome sequences was performed using the CLC Genomics Workbench v5.5. Sanger sequencing for variants validation was processed using a BigDye Terminator Cycle Sequencing Kit and an ABI 3730xI automated sequencer. Biological networks were created using Cytoscape (v2.8.3 and v3.0.2) and Pathway Studio 9.0 software.

Results: Nineteen sites were only observed in healthy individuals. Four proteins (NRXN2, KLKB1, KARS, and LAMA3) that harbour rarely observed single-nucleotide variants showed biological interactions that are associated with prion diseases and/or prion protein in our biological network analysis.

Conclusion: Through this study, we confirmed that individuals can have a CJD-free life, even if they carry a pathogenic E200K mutation. Our research provides a possible mechanism that involves a candidate protective factor; this could be exploited to prevent fCJD onset in individuals carrying E200K.

Keywords: PRNP, E200K-dependent fCJD, 85-year-old non-CJD individual with the E200K, Whole exome sequencing, Biological network analysis, Candidate protective factor against fCJD with E200K

\footnotetext{
*Correspondence: tenksy@korea.kr

${ }^{\dagger}$ Equal contributors

'Division of Zoonoses, Center for Immunology and Pathology, National Institute of Health, Korea Center for Disease Control and Prevention, Cheongju-si 363-700, Korea

Full list of author information is available at the end of the article
} 


\section{Background}

Transmissible spongiform encephalopathies (TSE), also called prion diseases, are rare fatal neurodegenerative disorders that affect humans and animals. TSE are characterized at the pathological level by abnormal accumulation of misfolding prion protein $\left(\mathrm{PrP}^{\mathrm{Sc}}\right)$ affecting the central nervous system (CNS) [1,2]. In most cases, transmission of $\mathrm{PrP}^{\mathrm{sc}}$ has been proven in animal models including primates and rodents; this has established $\mathrm{PrP}^{\mathrm{sc}}$ as the transmissible agent of diseases [3-5]. In humans, the causative agent is encoded by the prion protein gene $(P R N P)$ on chromosome 20p13. The incubation period for prion diseases observed in humans and animals is influenced by polymorphisms or mutations in PRNP. Pathogenic mutations in prion proteins that cause inherited prion diseases (IPD) are responsible for $10-15 \%$ of cases [6-8]. IPD have traditionally been classified as familial Creutzfeldt-Jakob disease (fCJD), fatal familial insomnia (FFI), and Gerstmann-Straussler-Scheinker syndrome (GSS). P102L, P105L, A117V, Y145stop, D178N, V180I, F198S, E200K, and V203I mutations in prion proteins are highly correlated with the pathogenicity of IPD [3-5,9-22].

The E200K substitution within PRNP is a major causative mutation of IPD $[6,23]$. The clinical features of fCJD patients with E200K are similar to those of sporadic CJD patients, and the median age of onset of CJD patients with E200K is 58, with a median disease duration of seven months [24]. The E200K mutation was first reported in 1989, and has since been found in North American Caucasians, Slovakians, Polish, German, Tunisian Jewish, Greek, Libyan Jews, and Chilean populations $[13,25]$. Although E200K is reportedly a causative mutation for fCJD, not all cases have a familial history. The mutation has also been observed in healthy individuals who are already above the median age for E200Kassociated CJD; remarkably, in one case, an individual over 80 years of age with the E200K mutant died of nonCJD related causes [26,27].

The reported penetrance for CJD with E200K is 56$59.5 \%$ in individuals below 80 years of age, and, depending on the population under study, rises to $80-100 \%$ in individuals above 80 years of age [13,27-29]. This demonstrates that most of the individuals with E200K can be regarded as suffering from CJD after the median age, but that some individuals appear to survive without the symptoms of CJD. This has led scientists to propose that genetic background can contribute to the delayed onset of CJD [26].

A Korean CJD patient with E200K who was presented to us was presumed to represent a sporadic case, since there was no previous family history of CJD [30]. Three generations of the patient's family $(n=12)$ provided us with their epidemiological details and whole blood samples; we investigated the PRNP genotypes of this pedigree and found that all of them were 129M homozygotes. E200K was observed in eight members of the family, including the patient. Five were 200E homozygotes, and 200K homozygotes were not observed.

Interestingly, the mother of the proband (born in 1927) was E200K heterozygous, but she did not have any symptoms related to neurodegenerative disorders, despite the fact that she was well over the median age for disease onset. This presentation makes the case extremely rare globally, and it is the first such case in Korea. We decided that follow-up studies of this family might further our understanding not only of the mechanisms by which E200K causes CJD, but also identify clusters of genetic polymorphisms that underlie neuroprotection.

Here, we report the genotype patterns and differences in the exome sequences between the above-mentioned family, CJD patients with E200K, and healthy individuals. We also discuss the biological network analysis undertaken to infer relationships between genotypes and prion disease onset.

\section{Results and discussion}

Two types of variant filtering strategies were used (see Methods). Validation studies revealed that 19 of 24 sites were validated as SNVs, with the rest being false positive (Table 1). Primer sequences of 24 sites are listed in Additional file 1: Table S1. All 19 validated SNVs were detected on autosomes. The biological data and official full name associated with each protein of the 19 SNVscontaining genes are listed in Additional file 2: Table S2 and Additional file 3: Table S3. None of the genes have previously been associated with prion diseases, with the exception of NRXN2, which was reported to be downregulated in mice infected with $\operatorname{PrP}^{\mathrm{sc}}$ [31]. Although the second variant filtering strategy was more relaxed than the first, only five variants met the criteria. However, all of them were confirmed as false positives. There are at least three hypothetical reasons to explain this. First, E200K may be the sole pathogenic mutation associated with CJD in these individuals. Second, CJD patients with E200K may indeed carry additional pathology-related mutations, but these may be already published, rather than de novo mutations. Third, the fact that we selected individuals with the E200K mutation in the first filtering strategy might influence the analysis with respect to prion disease onset or incubation period. Specifically, this may imply that the 85 -year-old non-CJD individual with the E200K mutation might also carry protective SNVs at other loci. E200K is unlikely to be the sole mutation that determines CJD onset, since there are some elderly individuals (age, up to 85 years) in this study. CJD is a rare neurodegenerative disorder, and there is a small possibility of disease identification in elderly individuals who carry E200K mutation and are healthy. 
Table 1 The information of the 24 sites that were directly sequenced and the genotypes of analysed individuals

\begin{tabular}{|c|c|c|c|c|c|c|c|c|c|c|c|c|c|c|}
\hline & & & & $\begin{array}{l}\text { PRNP mutation } \\
\text { Sample ID }\end{array}$ & $\begin{array}{c}\text { E200K } \\
\text { Patient } \\
\text { no. } 1\end{array}$ & $\begin{array}{c}\text { E200K } \\
\text { Patient } \\
\text { no. } 2 \\
\end{array}$ & $\begin{array}{l}\text { E200K } \\
\text { Patient } \\
\text { no. } 3\end{array}$ & $\begin{array}{c}\text { E200K } \\
\text { Family } \\
\text { no. } 1\end{array}$ & $\begin{array}{c}\text { WT } \\
\text { Family } \\
\text { no. } 2\end{array}$ & $\begin{array}{c}\text { E200K } \\
\text { Family } \\
\text { no. } 3\end{array}$ & $\begin{array}{c}\text { E200K } \\
\text { Family } \\
\text { no. } 4\end{array}$ & $\begin{array}{c}\text { E200K } \\
\text { Family } \\
\text { no. } 5\end{array}$ & $\begin{array}{c}\text { WT } \\
\text { Family } \\
\text { no. } 6\end{array}$ & $\begin{array}{c}\text { E200K } \\
\text { Family } \\
\text { no. } 7 \\
\end{array}$ \\
\hline \multirow[t]{10}{*}{$\begin{array}{c}\text { Variants } \\
\text { filtering strategy }\end{array}$} & Chr. & Position & Gene & $\begin{array}{l}\text { Year of birth } \\
\text { Ref./Obs. }\end{array}$ & 1948 & non-descript & 1935 & 1927 & 1950 & 1952 & 1955 & 1957 & 1962 & 1969 \\
\hline & 1 & $27,268,000$ & NUDC & $\mathrm{G} / \mathrm{A}$ & GG & GG & GG & $\mathrm{G} A$ & GG & $\mathrm{GA}$ & GA & $\mathrm{G} A$ & GG & GG \\
\hline & 1 & $42,049,603$ & HIVEP3 & $C / T$ & CC & CC & CC & $C T$ & $C T$ & CC & CC & CC & $C T$ & CC \\
\hline & 2 & $64,199,317$ & VPS54 & $\mathrm{G} / \mathrm{A}$ & GG & GG & GG & $\mathrm{G} A$ & GG & GG & $\mathrm{G} A$ & $\mathrm{G} A$ & $\mathrm{G} A$ & GG \\
\hline & 2 & $233,346,498$ & ECEL1 & $C / T$ & CC & CC & CC & $C T$ & CC & CC & CC & CC & $C T$ & CC \\
\hline & 3 & $124,896,625$ & SLC12A8 & $A / G$ & AA & AA & AA & $A G$ & $A G$ & AA & $A G$ & $A G$ & AA & AA \\
\hline & 4 & $187,153,290$ & KLKB1 & $C / T$ & CC & CC & CC & $C T$ & CC & CC & $C T$ & CC & CC & CC \\
\hline & 5 & $139,884,478$ & ANKHD1-EIF4EBP3 & $\mathrm{G} / \mathrm{C}$ & GG & GG & GG & GC & GG & GG & GG & GG & GC & GG \\
\hline & 6 & $159,185,617$ & SYTL3 & $\mathrm{T} / \mathrm{C}$ & $\pi$ & $\pi$ & $\pi$ & $\mathrm{TC}$ & TC & TC & $\pi$ & $\mathrm{TC}$ & $\pi$ & $\pi$ \\
\hline & 8 & $2,088,717$ & MYOM2 & $\mathrm{G} / \mathrm{T}$ & GG & GG & GG & GT & GT & GT & GT & GG & GT & GG \\
\hline \multirow[t]{12}{*}{ Filtering strategy 1} & 9 & $18,950,859$ & FAM154A & $C / T$ & CC & CC & CC & $C T$ & $C T$ & CT & CT & CC & $C T$ & CC \\
\hline & 10 & $24,831,649$ & KIAA1217 & $C / T$ & CC & CC & CC & $C T$ & $C T$ & CT & CC & CC & CC & CC \\
\hline & 11 & $27,016,411$ & FIBIN & $A / G$ & AA & $\mathrm{AA}$ & $A A$ & $A G$ & $\mathrm{FL}$ & AA & $A G$ & $A G$ & $A G$ & $A A$ \\
\hline & 11 & $36,250,774$ & LDLRAD3 & $\mathrm{G} / \mathrm{T}$ & GG & GG & GG & GT & GG & GT & GG & GG & GG & GG \\
\hline & 11 & $64,453,195$ & NRXN2 & $C / A$ & CC & CC & CC & $C A$ & CC & $C A$ & $C A$ & $C A$ & CC & CC \\
\hline & 13 & $39,588,100$ & PROSER1 & $\mathrm{G} / \mathrm{A}$ & GG & GG & GG & GA & GG & GG & GG & GG & GG & GG \\
\hline & 16 & $75,669,878$ & KARS & $A / G$ & AA & AA & AA & $A G$ & $A G$ & AA & AA & $A G$ & AA & AA \\
\hline & 17 & $59,489,425$ & C17orf82 & $C / G$ & CC & CC & CC & $C G$ & CG & $C G$ & CC & $C G$ & $C G$ & CC \\
\hline & 18 & $21,485,578$ & LAMA3 & $\mathrm{G} / \mathrm{C}$ & GG & GG & GG & GC & GC & GC & GC & GG & GC & GG \\
\hline & 19 & $4,359,190$ & MPND & $\mathrm{C} / \mathrm{T}$ & CC & CC & $C C$ & $C T$ & $C T$ & CT & $C C$ & CC & CC & $C C$ \\
\hline & 17 & $45,219,336$ & CDC27 & T/A & $\pi$ & $\pi$ & $\pi$ & $\pi$ & $\pi$ & $\pi$ & $\pi$ & $\pi$ & $\pi$ & $\pi$ \\
\hline & 19 & 501,786 & MADCAM1 & $C / A$ & CC & CC & CC & CC & CC & CC & CC & CC & CC & CC \\
\hline \multirow[t]{3}{*}{ Filtering strategy 2} & 19 & $50,510,999$ & \multirow{2}{*}{ VRK3 } & $A / T$ & $\pi$ & $\pi$ & $\pi$ & $\pi$ & $\pi$ & $\pi$ & $\pi$ & $\pi$ & $\pi$ & $\pi$ \\
\hline & 19 & $50,511,000$ & & $C / T$ & $\pi$ & $\pi$ & $\pi$ & $\pi$ & $\pi$ & $\pi$ & $\pi$ & $\pi$ & $\pi$ & $\pi$ \\
\hline & 19 & $52,096,053$ & AC018755.11 & T/A & $\mathrm{T} A$ & $\mathrm{~T} A$ & $\mathrm{~T} A$ & AA & $\mathrm{T} A$ & $\mathrm{~T} A$ & $\mathrm{~T} A$ & $\mathrm{~T} A$ & $\mathrm{~T} A$ & AA \\
\hline
\end{tabular}


Table 1 The information of the 24 sites that were directly sequenced and the genotypes of analysed individuals (Continued)

\begin{tabular}{|c|c|c|c|c|c|c|c|c|c|c|c|c|c|c|c|}
\hline & $\begin{array}{c}\text { WT } \\
\text { Family } \\
\text { no. } 8\end{array}$ & $\begin{array}{c}\text { E200K } \\
\text { Family } \\
\text { no. } 9\end{array}$ & $\begin{array}{c}\text { WT } \\
\text { Family } \\
\text { no. } 10\end{array}$ & $\begin{array}{l}\text { E200K } \\
\text { Family } \\
\text { no. } 11\end{array}$ & $\begin{array}{c}\text { WT } \\
\text { Family } \\
\text { no. } 12\end{array}$ & $\begin{array}{c}\text { WT } \\
\text { Normal } \\
\text { no. } 1\end{array}$ & $\begin{array}{c}\text { WT } \\
\text { Normal } \\
\text { no. } 2\end{array}$ & $\begin{array}{c}\text { WT } \\
\text { Normal } \\
\text { no. } 3\end{array}$ & $\begin{array}{c}\text { WT } \\
\text { Normal } \\
\text { no. } 4\end{array}$ & $\begin{array}{c}\text { WT } \\
\text { Normal } \\
\text { no. } 5\end{array}$ & $\begin{array}{c}\text { E219K } \\
\text { Normal } \\
\text { no. } 6\end{array}$ & $\begin{array}{c}\text { WT } \\
\text { Normal } \\
\text { no. } 7\end{array}$ & $\begin{array}{c}\text { WT } \\
\text { Normal } \\
\text { no. } 8\end{array}$ & $\begin{array}{c}\text { WT } \\
\text { Normal } \\
\text { no. } 9\end{array}$ & $\begin{array}{c}\text { WT } \\
\text { Normal } \\
\text { no. } 10\end{array}$ \\
\hline \multirow[t]{10}{*}{$\begin{array}{c}\text { Variants } \\
\text { filtering strategy }\end{array}$} & 1971 & 1975 & 1977 & 1981 & 1983 & 1969 & 1975 & 1976 & 1977 & 1980 & 1982 & 1983 & 1983 & 1984 & 1987 \\
\hline & GG & GG & GG & $\mathrm{G} A$ & GG & GG & GG & GG & GG & GG & GG & GG & GG & GG & GG \\
\hline & CC & CC & CC & CC & CC & CC & $C T$ & CC & CC & CC & CC & CC & CC & CC & CC \\
\hline & GG & GG & $\mathrm{G} A$ & $\mathrm{G} A$ & GG & GG & GG & $\mathrm{G} A$ & GG & GG & GG & GG & GG & GG & GG \\
\hline & CC & CC & CC & CC & CC & CC & $C T$ & CC & CC & $C T$ & $C T$ & CC & CC & CC & CC \\
\hline & $\mathrm{AA}$ & $\mathrm{AA}$ & $A G$ & $A G$ & $A G$ & $\mathrm{AA}$ & $\mathrm{AA}$ & $\mathrm{AA}$ & $\mathrm{AA}$ & $\mathrm{AA}$ & $\mathrm{AA}$ & $\mathrm{AA}$ & $\mathrm{AA}$ & $\mathrm{AA}$ & $\mathrm{AA}$ \\
\hline & $\mathrm{CC}$ & $\mathrm{CC}$ & $\mathrm{CC}$ & CC & CC & $C C$ & CC & $C C$ & CC & $\mathrm{CC}$ & CC & $C C$ & CC & CC & CC \\
\hline & GG & GG & GG & GG & GG & GG & GG & GG & GG & GG & GG & GG & GG & GG & GG \\
\hline & $\pi$ & $\pi$ & $\pi$ & $\mathrm{TC}$ & $\mathrm{TC}$ & $\pi$ & $\pi$ & $\pi$ & $\pi$ & $\pi$ & $\pi$ & $\pi$ & $\pi$ & $\pi$ & $\pi$ \\
\hline & GG & GG & $\mathrm{GT}$ & GG & GG & GG & GG & GG & GG & GG & GG & GG & GG & GG & GG \\
\hline \multirow[t]{12}{*}{ Filtering strategy 1} & CC & $\mathrm{CC}$ & $\mathrm{CC}$ & $\mathrm{CC}$ & $\mathrm{CC}$ & $\mathrm{CC}$ & CC & $\mathrm{CC}$ & $\mathrm{CC}$ & $\mathrm{CC}$ & $\mathrm{CC}$ & $\mathrm{CC}$ & $\mathrm{CC}$ & CC & CC \\
\hline & $\mathrm{CC}$ & $\mathrm{CC}$ & $\mathrm{CC}$ & $\mathrm{CC}$ & $\mathrm{CC}$ & $\mathrm{CC}$ & $\mathrm{CC}$ & $\mathrm{CC}$ & $\mathrm{CC}$ & $\mathrm{CC}$ & $\mathrm{CC}$ & $\mathrm{CC}$ & CC & $\mathrm{CC}$ & $\mathrm{CC}$ \\
\hline & AA & AA & AA & $A G$ & AA & AA & $\mathrm{AA}$ & $A G$ & AA & AA & AA & AA & AA & AA & $A G$ \\
\hline & GG & GG & GG & GG & GG & GG & GG & GG & GG & GG & GG & GG & GG & GG & GG \\
\hline & $\mathrm{CC}$ & $\mathrm{CC}$ & $\mathrm{CC}$ & $C A$ & CC & $C C$ & $C C$ & $\mathrm{CC}$ & CC & CC & CC & $\mathrm{CC}$ & $\mathrm{CC}$ & CC & CC \\
\hline & GG & GG & GG & GG & GG & GG & GG & GG & GG & GG & GG & GG & GG & GG & GG \\
\hline & AA & AA & AA & $\mathrm{AA}$ & $A G$ & $\mathrm{AA}$ & $\mathrm{AA}$ & $\mathrm{AA}$ & $\mathrm{AA}$ & $\mathrm{AA}$ & $\mathrm{AA}$ & $\mathrm{AA}$ & $\mathrm{AA}$ & $\mathrm{AA}$ & $\mathrm{AA}$ \\
\hline & $\mathrm{CC}$ & $\mathrm{CC}$ & $\mathrm{CC}$ & $\mathrm{CC}$ & $C G$ & $\mathrm{CC}$ & $\mathrm{CC}$ & $\mathrm{CC}$ & $\mathrm{CC}$ & $\mathrm{CC}$ & $\mathrm{CC}$ & $\mathrm{CC}$ & $\mathrm{CC}$ & CC & CC \\
\hline & GG & GG & GG & GG & GG & GG & GG & GG & GG & GG & GG & GG & GG & GG & GG \\
\hline & $\mathrm{CC}$ & $\mathrm{CC}$ & $\mathrm{CC}$ & $\mathrm{CC}$ & $\mathrm{CC}$ & $C C$ & $C C$ & $\mathrm{CC}$ & CC & $\mathrm{CC}$ & CC & $\mathrm{CC}$ & CC & $C C$ & CC \\
\hline & $\pi$ & $\pi$ & $\pi$ & $\pi$ & $\pi$ & $\pi$ & $\pi$ & $\pi$ & $\pi$ & $\pi$ & $\pi$ & $\pi$ & $\pi$ & $\pi$ & $\pi$ \\
\hline & $\mathrm{CC}$ & $\mathrm{CC}$ & $\mathrm{CC}$ & $\mathrm{CC}$ & $\mathrm{CC}$ & CC & $\mathrm{CC}$ & CC & CC & CC & CC & CC & CC & CC & CC \\
\hline \multirow[t]{3}{*}{ Filtering strategy 2} & $\pi$ & $\pi$ & $\pi$ & $\pi$ & $\pi$ & $\pi$ & $\pi$ & $\pi$ & $\pi$ & $\pi$ & $\pi$ & $\pi$ & $\pi$ & $\pi$ & $\pi$ \\
\hline & $\pi$ & $\pi$ & $\pi$ & $\pi$ & $\pi$ & $\pi$ & $\pi$ & $\pi$ & $\pi$ & $\pi$ & $\pi$ & $\pi$ & $\pi$ & $\pi$ & $\pi$ \\
\hline & $\mathrm{T} A$ & $\pi$ & $\mathrm{T} A$ & $\mathrm{~T} A$ & TA & AA & $\mathrm{T} A$ & $\mathrm{~T} A$ & $\pi$ & AA & $\pi$ & $\mathrm{T} A$ & $\mathrm{~T} A$ & $\mathrm{~T} A$ & $\pi$ \\
\hline
\end{tabular}


Thus, factors that either cause or protect against CJD might be discovered by comparing the exome of such individuals to other groups. In light of these considerations, we discarded the first two hypotheses and instead focused on the third possibility.

The 63-year-old proband (Case 1) is the eldest progeny of an 84-year-old non-CJD individual with the E200K mutation (Family Member 1, hereafter FM1); the rest of the progeny are younger than the proband by about 217 years. The 19 validated SNVs were not found in the proband and their sibling, which is expected as all mutations observed in the proband were filtered during the first filtering strategy. Between 5 and 10 variations were observed in the other siblings. FM7 and FM9 are heterozygous for E200K, and FM8 is homozygous for the wildtype E200 variant. Nucleotide variants in all three CJD patients with E200K were homozygous, and identical to the reference nucleotide sequence in dbSNP 132; the single-nucleotide variations (SNVs) in the mother of the proband were heterozygous and contained SNVs that have not been previously reported for dbSNP 132 . Nucleotide variations in PROSER1 were only observed in FM1, but the biological functions of this proline and serine-rich protein are unknown. We also found SNVs in NUDC, $K L K B 1$, and NRXN2; these were specifically present in non-CJD E200K individuals, but not in CJD patients with E200K counterparts. SNVs in 10 healthy individuals with no family history of CJD were observed in four genes (HIVEP3, VPS54, ECEL1, and FIBIN). Thus, these four SNVs were considered as relatively common among the general Korean population.

We used biological networking programs to gain new insight into possible mechanisms that protect individuals carrying E200K against CJD. The 19 proteins associated with SNVs in our study, and 5 proteins that are reported as prion disease-related, such as PRNP, prion protein doublet (PRND), prion protein testis-specific (PRNT), shadow of prion protein (SPRN), and apolipoprotein $\mathrm{E}$ (APOE), were used as seed proteins.

A total of 104 nodes, including 24 seed nodes, were identified (Figure 1). The average number of neighbours of nodes was 4.327, with the exception of PRNT, which

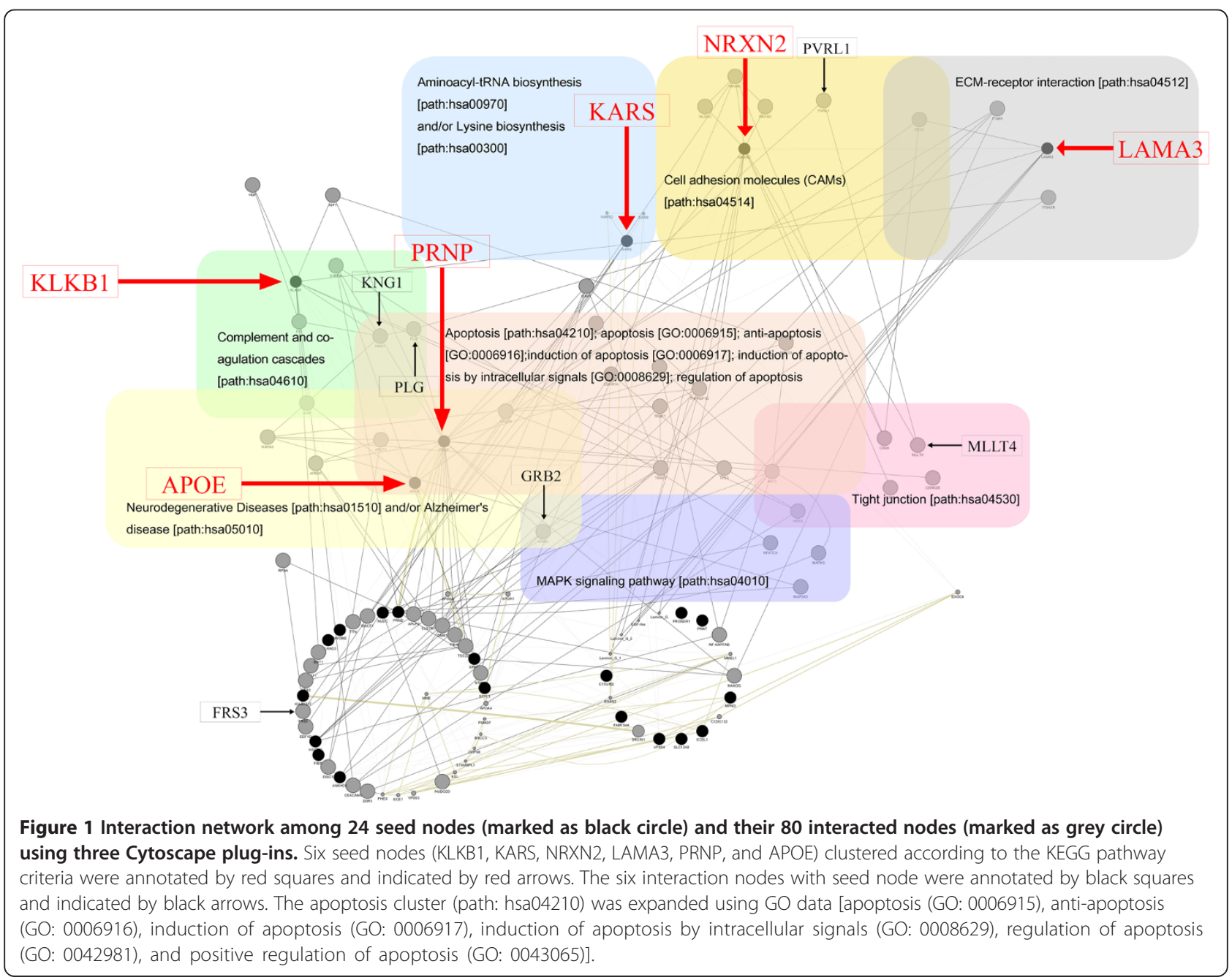


was isolated from the others. Among the 19 proteins harbouring validated SNVs, only four of them (KLKB1, KARS, NRXN2, and LAMA3) were clustered by Kyoto Encyclopedia of Genes and Genomes (KEGG) pathway criteria.

PRNP and APOE, which are within the neurodegenerative disorder and apoptosis-related seed nodes, were linked with Kininogen1 (KNG1) and plasminogen (PLG), which are apoptosis- and complement and coagulation cascade-related proteins [32-34]. KNG1 was linked with KLKB1, which was one of the seed nodes [35-39]. LAMA3 was also linked with PLG in our study. Consistent with this, LAMA3 is reported to contain a cleavage site for plasmin, the activated form of PLG [40].

PRNP has been previously linked with growth factor receptor bound protein 2 (GRB2) [41]. GRB2 is related to proteins that are implicated in neurodegenerative diseases (path: hsa01510), MAPK-signalling pathway (path: hsa04010), and Huntington's disease (path: hsa05040). GRB2 directly interacts with FRS3 [42], which is itself related to proteins involved in the fibroblast growth factor receptor signalling pathway, and signal transduction (GO: 0008543 and 0007165, respectively). FRS3 interacts with KARS, which is one of the seed proteins in the current study [43]. However, only a low-level biological interaction between FRS3 and KARS was reported. Hence, the relevance of KARS to prion disease at this stage remains unclear.
Interaction between PRNP and PVRL1 (also called PRR) was observed, although a strong relationship between the two was not evident from the publication [44]. Although PRNP was previously associated with cell adhesion molecules (CAMs) such as neural CAM1 (N-CAM1), neural CAM2 (N-CAM2) and neural adhesion molecule F3 (contactin1) [44], there are no reports of a direct relationship between PRNP and PVRL1. Thus, we believe the PRNP/ PVRL1 interaction was false. PVRL1 was linked with MLLT4, and a previous report says that it interacts with MLLT4 (also called Afadin), a PDZ domain-containing protein [45-47]. MLLT4 was linked to NRXN2, which is one of the seed proteins in this study [48]. It is known that C-terminal peptides of the NRXN2 sequence can interact with the PDZ domain of MLLT4.

Biological network analysis using Pathway studio v9 identified four proteins, namely, KLKB1, LAMA3, KARS, and VPS54 (Figure 2). VPS54 and KLKB1 were identified since they have interactions with tumour necrosis factor (TNF), rather than with prion diseases and/or prion protein; they were thus excluded from the network analysis. LAMA3 and KARS were identified because of indirect interaction with prion protein and prion diseases; they were therefore subjected to follow-up analysis to determine whether they were associated with mechanisms that protect against prion disease.

$L A M A 3$ is located at $18 \mathrm{q} 11.2$, and a de novo mutation $(\mathrm{K} 2180 \mathrm{~N})$ was observed in this study. The C-terminal

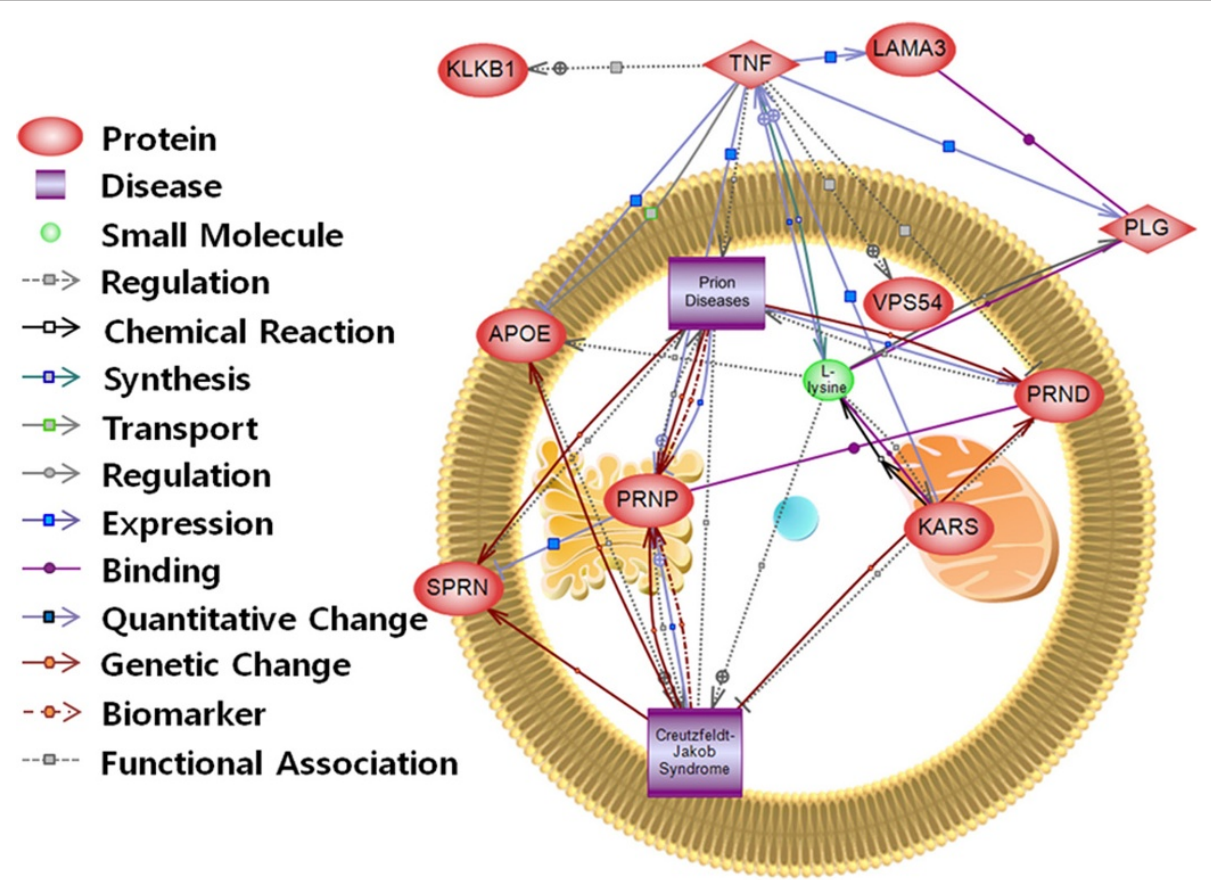

Figure 2 Interaction network using Pathway studio. Interactions between nodes are denoted by coloured arrows or lines. Seed nodes are marked as red circles. PLG and TNF are shown as significant interactions with the seed nodes, PRNP, prion diseases were marked as diamond-square. 
part of LAMA3 forms a compact globular domain, called the $\mathrm{G}$ domain, which is divided into subdomains G1-G5; the G1 subdomain is a plasmin-binding site, and the G4 subdomain contains a plasmin cleavage site [40]. PLG is reported to bind a lysine-rich portion of $\mathrm{PrP}$, and in doing so can stimulate propagation of $\operatorname{PrP}^{\mathrm{sc}}$. L-Lysine has a role in blocking plasminogen-mediated stimulation of $\operatorname{PrP}^{\mathrm{sc}}$ propagation $[49,50]$.

Aminoacyl-tRNA synthetases (ARSs) ligate specific amino acids to their cognate tRNAs for protein synthesis, and human lysyl-tRNA synthetase (KARS) are the one of the ARSs for lysine. The Y201H mutation in KARS was detected as a de novo mutant; however, this mutation has previously been published in dbSNP build 134 as rs150529876. However, rs150529876 is scarcely found in East Asian populations referred to in the 1000 Genome allele frequencies data, which confirms that it is a very rarely detected variant in human population. The $\mathrm{Y} 201 \mathrm{H}$ mutation might alter the levels of lysine in the human body, and may favour the interaction between PLG and lysine, instead of with $\operatorname{PrP}^{\mathrm{sc}}$. Possibly, this might ultimately change the incubation period prior to CJD onset.

KARS is also known to induce secretion of the proinflammatory cytokine TNF from macrophages [51]. Lack of follicular dendritic cells (FDCs) was observed in TNFdeficient $\left(\mathrm{TNF}^{-/}\right)$mice [52], and these animals do not accumulate scrapie in their spleens upon challenge with the ME7 scrapie strain [53]. This is likely since mature FDCs are required for $\operatorname{Pr}^{\mathrm{sc}}$ aggregation. Thus, we suggest that the $\mathrm{Y} 201 \mathrm{H}$ mutation in KARS engenders a failure of TNF induction, which in turn prevents $\operatorname{PrP}^{\mathrm{sc}}$ accumulation. We consider that this mutant form of KARS leads to an increased incubation period for prion diseases.

\section{Conclusions}

In summary, we identified $19 \mathrm{SNVs}$ that were differentially present in a healthy, 86-year-old individual with E200K, and in CJD patients with E200K. Each of these 19 SNVs is a candidate protective factor against E200Kassociated CJD, since to date they were only observed in healthy individuals. However, longer follow-up studies of the family are required to definitively conclude that these 19 SNVs are CJD-protective factors. Our biological network analysis may also explain why FM1, who is the mother of the proband, does not have CJD symptoms, even though she has the E200K pathogenic mutation. Four proteins (NRXN2, KLKB1, KARS, and LAMA3) that harbour rarely observed SNVs have biological interactions that are associated with prion diseases and/or prion protein. However, we could not find significantly strong evidence that the other 15 proteins that harbour de novo SNVs had a biologically relevant association with prion diseases.
Through this study, we confirmed that individuals can have a CJD-free life, even if they harbour the pathogenic E200K mutation, and we provide possible protective mechanisms to explain this observation. Our research provides fundamental insight into the mechanisms that underlie the onset of prion disease, and suggests therapeutic strategies to treat E200K-associated CJD. We expect that ambiguous personal susceptibility on PRNP mutation causing fCJD can be defined through further studies of combined interpretation of biological network analysis derived from next-generation sequencing of individual genomes and clinical information.

\section{Methods \\ Subjects}

This study was approved by Institutional Review Board, Korea Centers for Disease Control and Prevention (IRB No. 2010-02CON-06-P). Written informed consent was obtained from the participants or legal guardian of each patient.

\section{Three CJD patients}

All three CJD patients with E200K were described in this study, and they were South Korean natives. Case 1 was born in 1948, and was presumed to have developed symptoms in August 2011. The birth date of CJD Case 2 was not recorded. The patient first showed symptoms of CJD on January 8, 2011. Case 3 was born in 1935, and the patient first showed symptoms of CJD on March 14, 2010. All patients informed us that did not have a family history of CJD; thus, all three CJD patients with the E200K mutation were regarded as sporadic-like cases.

\section{2 individuals in the family of case 1}

The three-generation family $(n=12)$ of case 1 generously contributed their time and materials to this study. The pedigree of the family was described using the GenoPro (http://www.genopro.com) pedigree drawing program (Figure 3).

\section{Healthy Korean exome sequences}

The exome sequences of 14 healthy Koreans stored in Division of Center for Genome Science in KNIH were used as control for variation filtering.

\section{0 randomly selected healthy individuals}

Since DNA samples for 14 healthy Korean described above were not stored, DNA samples from 10 healthy individual volunteers in their 20s-40s were selected for variant validation.

\section{DNA extraction}

gDNA samples were extracted from the individuals described above (except for 14 healthy Korean samples) for 


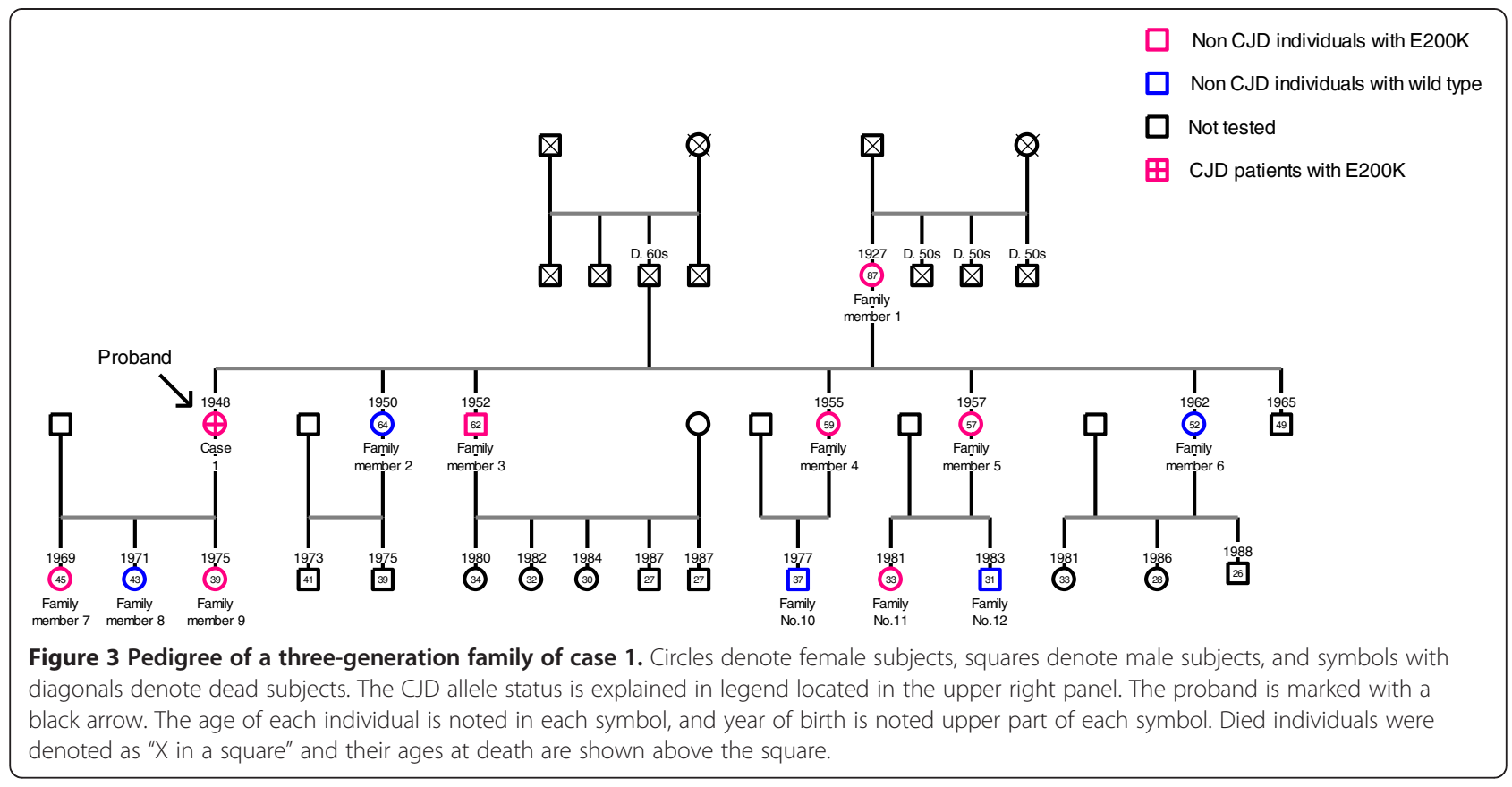

variant filtering. Total DNA was isolated from whole blood samples using QIAamp DNA Blood Mini Kit (QIAGEN, Korea), according to the manufacturer's instructions. The extracted DNA was quantified using the Quant-iT PicoGreen dsDNA kit (Invitrogen, Carlsbad, CA).

\section{Exome sequencing}

Exome sequencing of the three CJD patients with E200K and 11 of the three-generation family of Case 1 were performed using the Solexa sequencing technology platform (HiSeq2000, Illumina, San Diego, CA), following the manufacturer's instructions. Exome sequencing of FM 7 was excluded since the quantity of gDNA $(<1 \mu \mathrm{g})$ was not sufficient in this case.

\section{Exome capture libraries and sequencing}

Three micrograms of the extracted DNA was randomly sheared using the Covaris System to generate 150-bp inserts. The sonicated DNA was end-repaired using T4 DNA polymerase and Klenow polymerase, and Illumina paired-end adaptor oligonucleotides were ligated to the sticky ends. Ligated DNA was size-selected for lengths between 200 and $250 \mathrm{bp}$. The purified DNA library was hybridized with SureSelect Human All Exons probe set (Agilent, Santa Clara, CA) to capture 50-Mb targeted exons following the manufacturer's instructions. Captured libraries were loaded onto the Illumina flow cell for sequencing on the Illumina HiSeq2000 instrument.

\section{Mapping and variations detection}

Sequence reads mapping was performed using CLC Genomics Workbench v5.5 (CLC Bio, Aarhus, Denmark) with the human reference genome (GRCh37/hg19, dbSNP build 132). Variant calling was performed with default parameters. In the mapping steps, an average of 5.6 gigabases of uniquely mapping reads were obtained, and 3.6 gigabases of uniquely mapping reads were aligned on target per sample, with an average of $64 \%$ of all reads mapping on target. Approximately $86 \%$ of bases have basecall quality scores were over Q30 (Phred score of 30) per sample.

\section{Variants filtering}

Only variants showing different variation frequencies between CJD patients and non-CJD individuals were selected. Next, only non-synonymous variants were selected, and then variant filtering was performed based on the hypothesis that the mutation underlying familial CJD with E200K was rarely present in the general population (Figure 4). Nucleotide variants presented in dbSNP build 132 were filtered out. We then excluded variants having depth of coverage below $20 \times$. Two types of variant filtering strategy were used. For the first filtering strategy, observed nucleotide variants in the 85-year-old non-CJD individual with E200K, but not observed in the three CJD patients with E200K. For the second filtering strategy, we only observed nucleotide variants in the three CJD patients with E200K. However, none of the sites were selected for the second strategy. Thus, the second filtering condition was more relaxed than that of the first. This meant that five variants were selected even though coverage was lower than $20 \times$. A total of 48 sites were selected, but only 24 sites were analysed in the follow-up validation process, as we experienced PCR primer failures with the remaining samples. 
Stage 1. Observe all variants in 3 CJD patients with E200K and/or 1 non-CJD individual with E200K ( 85 years olds)

Stage 2. Exclude nonfunctional variants

Stage 3. Exclude if in dbSNP Build 132

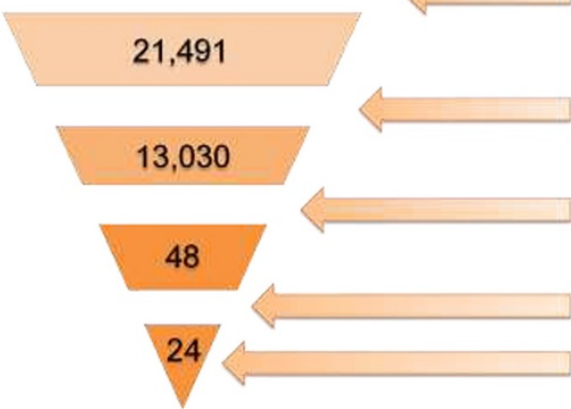

Stage 4. Select if showing different variants frequency between CJD patients and 1 non-CJD individual with E200K

Stage 5 . Select variants if coverage was over $20 x$ and frequency were between $12 \%$ and $88 \%$

\section{Stage 6. Exclude if $P C R$ primer design was failed}

Stage 7 . Finally selected sites for variants validation

Figure 4 Variant filtering strategy. Overview of variant filtering of whole exome sequencing data.

\section{Validation of selected variants}

PCR primer sets and their annealing temperature are described in Additional file 1: Table S1. The final volume of the PCR was $10 \mu \mathrm{l}$, consisting of $10 \mathrm{ng}$ DNA, $0.5 \mu \mathrm{M}$ each primer pair, $0.25 \mathrm{mM}$ dNTPs, $3 \mathrm{mM} \mathrm{MgCl}_{2}$, $1 \mu \mathrm{l}$ of $10 \times$ reaction buffer, and $0.25 \mathrm{U}$ Taq DNA polymerase (Intron Biotechnology, Seongnam-Si, Gyeonggi-do, Korea). The PCR reaction was performed using 96-Well GeneAmp PCR System 9700 (Applied Biosystems, Foster City, CA) under the following conditions: initial denaturation at $94^{\circ} \mathrm{C}$ for $5 \mathrm{~min}$, followed by 35 cycles of denaturation at $94^{\circ} \mathrm{C}$ for $30 \mathrm{~s}$, annealing at $60^{\circ} \mathrm{C}$ for $30 \mathrm{~s}$, initial extension at $72^{\circ} \mathrm{C}$ for $30-60 \mathrm{~s}$, and final extension at $72^{\circ} \mathrm{C}$ for $10 \mathrm{~min}$. The PCR products were purified using a MultiScreen 384-PCR Filter Plate (Millipore, Billerica, MA). The purified products were then sequenced using a BigDye Terminator Cycle Sequencing Kit and an ABI 3730xl automated sequencer (Applied Biosystems, Foster City, CA). The sequencing primers were the same as those used for the PCR amplification.

\section{Biological network analysis}

\section{1) Cytoscape (http://www.cytoscape.org/)}

Cytoscape and three plug-ins, MiMI v3.1.1 (http://mimi. ncibi.org/MimiWeb/main-page.jsp), GeneMania v3.2.1 (http://www.genemania.org/), and Agilent Literature Search 3.0.3 beta (http://www.agilent.com/labs/research/ litsearch.html) were used to construct a biological network. Due to compatibility issues, we used MiMI in Cytoscape v2.8.3 rather than v3.0.2. Next, all three networks were merged and visualized in Cytoscape v3.0.2.
All nodes were clustered automatically using listed KEGG pathway criteria and the MiMI plug-in.

2) Pathway Studio v9 (Ariadne, Rockville, MD)

The second set of biological networks in this study was created using Pathway Studio 9.0 software (http://www. elsevier.com/online-tools/pathway-studio). The molecular interaction data were extracted by Elsevier's MedScan text-mining software, which contains almost 30 million biological articles and abstracts.

\section{Additional files}

Additional file 1: Table S1. Primer sequences for variants validation. Additional file 2: Table S2. Biological information of the 19 proteins harbouring the 19 validated sites. Known biological functions of the proteins were obtained from Kyoto Encyclopedia of Genes and Genomes (KEGG) and The Gene Ontology (GO) project (http://www.geneontology.org/).

Additional file 3: Table S3. The information of 19 validated sites. Five sites that were false-positive were not recorded in this table. "-" means that there is no data for dbSNP 138. East Asians, Americans, Europeans, Africans were denoted as ASN, AMR, EUR, and AFR respectively. Chromosome, reference alleles and observed alleles in this study were denoted as Chr., Ref., and Obs. respectively.

\section{Abbreviations}

fCJD: Familial Creutzfeldt-Jakob disease; IPD: Inherited prion diseases; PRNP: Prion protein gene; SNVs: Single nucleotide variants; FFI: Fatal familial insomnia; GSS: Gertsmann-striussler-scheinker syndrome; FM: Family Member; PRND: Prion protein doublet; PRNT: Prion protein testis specific; SPRN:

Shadow of prion protein; PCR: Polymerase chain reaction.

\section{Competing interests}

The authors' declare that they have no competing interests. 


\section{Authors' contributions}

SML, MC and SYK designed the study. SML and MC collected the data and performed data analysis. KJH, YRJ discussed and interpreted results. JWH and SYK collected epidemiological details and whole blood samples for the study. JSP, CKK, SC, and JL assisted with the analysis. SML, MC, and SYK wrote the manuscript. All authors read and approved the final manuscript.

\section{Acknowledgments}

The exome sequence of 14 healthy Korean (unpublished) were supported by the Center for Genome Science, Korea NIH. We are especially grateful to the family who generously contributed their time and materials to this study. We thank Dr. SangYun Kim and Dr. Yooseok Kwon, (Department of Neurology, Seoul National University Bundang Hospital, Seoul National University College of Medicine, Seongnam, South Korea) for their collaboration in collecting epidemiological details and whole blood samples for the study. This research was funded by Korea Centers for Disease Control and Prevention (KCDC), Ministry of Health \& Welfare (project number, 2010-N53002-00).

\section{Author details}

'Division of Zoonoses, Center for Immunology and Pathology, National Institute of Health, Korea Center for Disease Control and Prevention, Cheongju-si 363-700, Korea. ${ }^{2}$ Division of Bio-Medical Informatics, Center for Genome Science, National Institute of Health, Korea Center for Disease Control and Prevention, Cheongju-si 363-700, Korea. ${ }^{3}$ Department of Agricultural Biotechnology, Animal Biotechnology Major, Seoul National University, Seoul 151-921, Korea. ${ }^{4}$ Division of Molecular and Life science, Hanyang University, Seoul 133-791, Korea.

Received: 6 May 2014 Accepted: 15 August 2014

Published: 22 August 2014

\section{References}

1. Kitamoto T, Muramoto T, Mohri S, Doh-Ura K, Tateishi J: Abnormal isoform of prion protein accumulates in follicular dendritic cells in mice with Creutzfeldt-Jakob disease. J Virol 1991, 65(11):6292-6295.

2. Taraboulos A, Serban D, Prusiner SB: Scrapie prion proteins accumulate in the cytoplasm of persistently infected cultured cells. J Cell Biol 1990, 110(6):2117-2132.

3. Tateishi J, Kitamoto T: Inherited prion diseases and transmission to rodents. Brain Pathol 1995, 5(1):53-59

4. Collins S, McLean CA, Masters CL: Gerstmann-Straussler-Scheinker syndrome, fatal familial insomnia, and kuru: a review of these less common human transmissible spongiform encephalopathies. J Clin Neurosci 2001, 8(5):387-397.

5. Tateishi J, Kitamoto $\mathrm{T}$, Hoque MZ, Furukawa $\mathrm{H}$ : Experimental transmission of Creutzfeldt-Jakob disease and related diseases to rodents. Neurology 1996, 46(2):532-537.

6. Mead S: Prion disease genetics. Eur J Hum Genet 2006, 14(3):273-281.

7. Mastrianni JA: The genetics of prion diseases. Genet Med 2010, 12(4):187-195.

8. Panegyres PK, Goh JG, Goldblatt J: Codon 200 mutation of the prion gene: genotype-phenotype correlations. J Neuro/ 2012, 259(12):2579-2584.

9. Kitamoto T, Tateishi J: Human prion diseases with variant prion protein. Philos Trans R Soc Lond B Biol Sci 1994, 343(1306):391-398.

10. Kobayashi S, Saito Y, Maki T, Murayama S: Cortical propagation of Creutzfeldt-Jakob disease with codon 180 mutation. Clin Neurol Neurosurg 2010, 112(6):520-523.

11. Goldfarb LG, Brown P, Haltia M, Cathala F, McCombie WR, Kovanen J, Cervenakova L, Goldin L, Nieto A, Godec MS, Asher DM, Gajdusek DC: Creutzfeldt-Jakob disease cosegregates with the codon 178Asn PRNP mutation in families of European origin. Ann Neurol 1992, 31(3):274-281.

12. Goldfarb LG, Haltia M, Brown P, Nieto A, Kovanen J, McCombie WR, Trapp S, Gajdusek DC: New mutation in scrapie amyloid precursor gene (at codon 178) in Finnish Creutzfeldt-Jakob kindred. Lancet 1991, 337(8738):425.

13. Goldfarb LG, Brown P, Mitrova E, Cervenakova L, Goldin L, Korczyn AD, Chapman J, Galvez S, Cartier L, Rubenstein R, Gajdusek DC: CreutzfeldtJacob disease associated with the PRNP codon 200Lys mutation: an analysis of 45 families. Eur J Epidemiol 1991, 7(5):477-486.

14. Medori R, Tritschler HJ, LeBlanc A, Villare F, Manetto V, Chen HY, Xue R, Leal S, Montagna P, Cortelli P, Tinuper P, Avoni P, Mochi M, Baruzzi A, Hauw JJ, Ott J, Lugaresi E, Autilio-Gambetti L, Gambetti P: Fatal familial insomnia, a prion disease with a mutation at codon 178 of the prion protein gene. N Engl J Med 1992, 326(7):444-449.

15. Synofzik M, Bauer P, Schols L: Prion mutation D178N with highly variable disease onset and phenotype. J Neurol Neurosurg Psychiatry 2009, 80(3):345-346

16. Peoc'h K, Manivet $P$, Beaudry $P$, Attane $F$, Besson G, Hannequin D, Delasnerie-Laupretre N, Laplanche JL: Identification of three novel mutations (E196K, V203I, E211Q) in the prion protein gene (PRNP) in inherited prion diseases with Creutzfeldt-Jakob disease phenotype. Hum Mutat 2000, 15(5):482.

17. Shi Q, Chen C, Wang XJ, Zhou W, Wang JC, Zhang BY, Gao C, Han J, Dong XP: Rare V203I mutation in the PRNP gene of a Chinese patient with Creutzfeldt-Jakob disease. Prion 2013, 7(3):259-262.

18. Kitamoto $T$, Amano N, Terao $Y$, Nakazato $Y$, Isshiki T, Mizutani $T$, Tateishi J: A new inherited prion disease (PrP-P105L mutation) showing spastic paraparesis. Ann Neurol 1993, 34(6):808-813.

19. Hsiao K, Baker HF, Crow TJ, Poulter M, Owen F, Terwilliger JD, Westaway D, Ott J, Prusiner SB: Linkage of a prion protein missense variant to Gerstmann-Straussler syndrome. Nature 1989, 338(6213):342-345.

20. Doh-ura K, Tateishi J, Sasaki H, Kitamoto T, Sakaki Y: Pro--leu change at position 102 of prion protein is the most common but not the sole mutation related to Gerstmann-Straussler syndrome. Biochem Biophys Res Commun 1989, 163(2):974-979.

21. Kitamoto $T$, lizuka $R$, Tateishi J: An amber mutation of prion protein in Gerstmann-Straussler syndrome with mutant PrP plaques. Biochem Biophys Res Commun 1993, 192(2):525-531.

22. Hsiao K, Dlouhy SR, Farlow MR, Cass C, Da Costa M, Conneally PM, Hodes ME, Ghetti B, Prusiner SB: Mutant prion proteins in Gerstmann-StrausslerScheinker disease with neurofibrillary tangles. Nat Genet 1992, 1(1):68-71.

23. Kovacs GG, Puopolo M, Ladogana A, Pocchiari M, Budka H, Van Duijn C, Collins SJ, Boyd A, Giulivi A, Coulthart M, Delasnerie-Laupretre N, Brandel JP, Zerr I, Kretzschma HA, de Pedro-Cuesta J, Calero-Lara M, Glatzel M, Aguzzi A, Bishop M, Knight R, Belay G, Will R, Mitrova E: Genetic prion disease: the EUROCJD experience. Hum Genet 2005, 118(2):166-174.

24. Kahana E, Zilber N, Abraham M: Do Creutzfeldt-Jakob disease patients of Jewish Libyan origin have unique clinical features? Neurology 1991, 41(9):1390-1392.

25. Goldgaber D, Goldfarb LG, Brown P, Asher DM, Brown WT, Lin S, Teener JW, Feinstone SM, Rubenstein R, Kascsak RJ, Boellaard JW, Gajdusek DC: Mutations in familial Creutzfeldt-Jakob disease and GerstmannStraussler-Scheinker's syndrome. Exp Neurol 1989, 106(2):204-206.

26. Hsiao K, Meiner Z, Kahana E, Cass C, Kahana I, Avrahami D, Scarlato G, Abramsky O, Prusiner SB, Gabizon R: Mutation of the prion protein in Libyan Jews with Creutzfeldt-Jakob disease. N Engl J Med 1991, 324(16):1091-1097.

27. Spudich S, Mastrianni JA, Wrensch M, Gabizon R, Meiner Z, Kahana I, Rosenmann H, Kahana E, Prusiner SB: Complete penetrance of CreutzfeldtJakob disease in Libyan Jews carrying the E200K mutation in the prion protein gene. Mol Med 1995, 1(6):607-613.

28. Mitrova E, Belay G: Creutzfeldt-Jakob disease with E200K mutation in Slovakia: characterization and development. Acta Virol 2002, 46(1):31-39.

29. Chapman J, Ben-Israel J, Goldhammer Y, Korczyn AD: The risk of developing Creutzfeldt-Jakob disease in subjects with the PRNP gene codon 200 point mutation. Neurology 1994, 44(9):1683-1686.

30. Kwon Y, Yang Y, Kim S: A case of familial CJD with a PRNP E200K mutation. Alzheimers Dement 2012, 8(4):684

31. Sorensen G, Medina S, Parchaliuk D, Phillipson C, Robertson C, Booth SA Comprehensive transcriptional profiling of prion infection in mouse models reveals networks of responsive genes. BMC Genomics 2008, 9:114.

32. Selim TE, Ghoneim HR, Uknis AB, Colman RW, DeLa Cadena RA: Highmolecular-mass and low-molecular-mass kininogens block plasmininduced platelet aggregation by forming a complex with kringle 5 of plasminogen/plasmin. Eur J Biochem 1997, 250(2):532-538.

33. Fischer MB, Roeckl C, Parizek P, Schwarz HP, Aguzzi A: Binding of diseaseassociated prion protein to plasminogen. Nature 2000, 408(6811):479-483.

34. Bass R, Ellis V: Cellular mechanisms regulating non-haemostatic plasmin generation. Biochem Soc Trans 2002, 30(2):189-194.

35. Thompson RE, Mandle R Jr, Kaplan AP: Studies of binding of prekallikrein and Factor $\mathrm{XI}$ to high molecular weight kininogen and its light chain. Proc Natl Acad Sci U S A 1979, 76(10):4862-4866.

36. Herwald H, Jahnen-Dechent W, Alla SA, Hock J, Bouma BN, Muller-Esterl W: Mapping of the high molecular weight kininogen binding site of 
prekallikrein. Evidence for a discontinuous epitope formed by distinct segments of the prekallikrein heavy chain. J Biol Chem 1993, 268(19):14527-14535.

37. Page JD, You JL, Harris RB, Colman RW: Localization of the binding site on plasma kallikrein for high-molecular-weight kininogen to both apple 1 and apple 4 domains of the heavy chain. Arch Biochem Biophys 1994 314(1):159-164.

38. Renne T, Dedio J, Meijers JC, Chung D, Muller-Esterl W: Mapping of the discontinuous H-kininogen binding site of plasma prekallikrein. Evidence for a critical role of apple domain-2. J Biol Chem 1999, 274(36):25777-25784

39. Kerbiriou DM, Griffin JH: Human high molecular weight kininogen. Studies of structure-function relationships and of proteolysis of the molecule occurring during contact activation of plasma. J Biol Chem 1979, 254(23):12020-12027.

40. Goldfinger LE, Jiang L, Hopkinson SB, Stack MS, Jones JC: Spatial regulation and activity modulation of plasmin by high affinity binding to the $G$ domain of the alpha 3 subunit of laminin-5. J Biol Chem 2000, 275 (45):34887-34893.

41. Spielhaupter C, Schatzl HM: PrPC directly interacts with proteins involved in signaling pathways. J Biol Chem 2001, 276(48):44604-44612.

42. Yamada M, Suzuki K, Mizutani M, Asada A, Matozaki T, Ikeuchi T, Koizumi S, Hatanaka $\mathrm{H}$ : Analysis of tyrosine phosphorylation-dependent proteinprotein interactions in TrkB-mediated intracellular signaling using modified yeast two-hybrid system. J Biochem 2001, 130(1):157-165.

43. Stelzl U, Worm U, Lalowski M, Haenig C, Brembeck FH, Goehler H, Stroedicke M, Zenkner M, Schoenherr A, Koeppen S, Timm J, Mintzlaff S, Abraham C, Bock N, Kietzmann S, Goedde A, Toksöz E, Droege A, Krobitsch $\mathrm{S}$, Korn B, Birchmeier W, Lehrach $\mathrm{H}$, Wanker EE: A human protein-protein interaction network: a resource for annotating the proteome. Cell 2005, 122(6):957-968.

44. Schmitt-Ulms G, Hansen K, Liu J, Cowdrey C, Yang J, DeArmond SJ, Cohen FE, Prusiner SB, Baldwin MA: Time-controlled transcardiac perfusion cross-linking for the study of protein interactions in complex tissues. Nat Biotechnol 2004, 22(6):724-731.

45. Takahashi K, Nakanishi H, Miyahara M, Mandai K, Satoh K, Satoh A, Nishioka H, Aoki J, Nomoto A, Mizoguchi A, Takai Y: Nectin/PRR: an immunoglobulin-like cell adhesion molecule recruited to cadherin-based adherens junctions through interaction with Afadin, a PDZ domaincontaining protein. J Cell Biol 1999, 145(3):539-549.

46. Miyahara M, Nakanishi H, Takahashi K, Satoh-Horikawa K, Tachibana K, Takai $Y$ : Interaction of nectin with afadin is necessary for its clustering at cellcell contact sites but not for its cis dimerization or trans interaction. J Biol Chem 2000, 275(1):613-618

47. Reymond N, Garrido-Urbani S, Borg JP, Dubreuil P, Lopez M: PICK-1: a scaffold protein that interacts with Nectins and JAMs at cell junctions. FEBS Lett 2005, 579(10):2243-2249.

48. Hock B, Bohme B, Karn T, Yamamoto T, Kaibuchi K, Holtrich U, Holland S, Pawson T, Rubsamen-Waigmann H, Strebhardt K: PDZ-domain-mediated interaction of the Eph-related receptor tyrosine kinase EphB3 and the ras-binding protein AF6 depends on the kinase activity of the receptor. Proc Natl Acad Sci U S A 1998, 95(17):9779-9784.

49. Mays $C E$, Ryou C: Plasminogen stimulates propagation of proteaseresistant prion protein in vitro. FASEB J 2010, 24(12):5102-5112.

50. Mays $C E$, Ryou C: Plasminogen: A cellular protein cofactor for PrPSC propagation. Prion 2011, 5(1):22-27.

51. Park SG, Ewalt KL, Kim S: Functional expansion of aminoacyl-tRNA synthetases and their interacting factors: new perspectives on housekeepers. Trends Biochem Sci 2005, 30(10):569-574.

52. Pasparakis M, Alexopoulou L, Episkopou V, Kollias G: Immune and inflammatory responses in TNF alpha-deficient mice: a critical requirement for TNF alpha in the formation of primary B cell follicles, follicular dendritic cell networks and germinal centers, and in the maturation of the humoral immune response. J Exp Med 1996, 184(4):1397-1411.

53. Mabbott NA, Williams A, Farquhar CF, Pasparakis M, Kollias G, Bruce ME: Tumor necrosis factor alpha-deficient, but not interleukin-6-deficient, mice resist peripheral infection with scrapie. J Virol 2000, 74(7):3338-3344.

doi:10.1186/1755-8794-7-52

Cite this article as: Lee et al:: Biological network inferences for a protection mechanism against familial Creutzfeldt-Jakob disease with E200K pathogenic mutation. BMC Medical Genomics 2014 7:52.

\section{Submit your next manuscript to BioMed Central and take full advantage of:}

- Convenient online submission

- Thorough peer review

- No space constraints or color figure charges

- Immediate publication on acceptance

- Inclusion in PubMed, CAS, Scopus and Google Scholar

- Research which is freely available for redistribution

Submit your manuscript at www.biomedcentral.com/submit
C Biomed Central 